\title{
Echocardiographic characterization of hypertrophic cardiomyopathy in Chinese patients with myosin-binding protein $\mathrm{C3}$ mutations
}

\author{
BEI ZHAO ${ }^{1}$, SHOULI WANG ${ }^{1}$, JINSONG CHEN ${ }^{2}$, YALI JI ${ }^{3}$, JING WANG $^{4}$, XIAOLI TIAN $^{5}$ and GUANG ZHI ${ }^{4}$ \\ ${ }^{1}$ Department of Cardiology, The 306th Hospital of Chinese People's Liberation Army, Beijing 100101; \\ ${ }^{2}$ Department of Cardiology, Xiamen University Affiliated to Dongnan Hospital, Zhangzhou, Fujian 363000; \\ ${ }^{3}$ Department of Information, The 306th Hospital of Chinese People's Liberation Army, Beijing 100101; \\ ${ }^{4}$ Department of Cardiology, Chinese People's Liberation Army General Hospital, Beijing 100853; \\ ${ }^{5}$ Human Population Genetic Institute of Molecular Medicine, Peking University, Beijing 100871, P.R. China
}

Received July 3, 2015; Accepted August 25, 2016

DOI: 10.3892/etm.2017.4089

\begin{abstract}
Hypertrophic cardiomyopathy (HCM) is a common autosomal dominant cardiac disease, affecting 1 in 500 people. Myosin-binding protein C3 (MyBPC3) gene mutations are the most common genetic cause of HCM. However, the prevalence of the $M y B P C 3$ gene mutation in Chinese patients with HCM, and their echocardiographic characteristics, remain unknown. In the present study, 48 Chinese patients with HCM were sequenced to identify the $M y B P C 3$ gene and were characterized by their clinical features using 2-dimensional echocardiography and real-time 3-dimensional echocardiography. Nine $M y B P C 3$ mutations were identified in seven unrelated patients out of 48 cases, which accounts for a $15 \%$ prevalence of $M y B P C 3$ mutations in Chinese patients with HCM. Family members of the seven patients were further tested and divided into the following two groups based on HCM phenotype and MyBPC3 mutations: Positive genotype with left ventricular (LV) hypertrophy $(\mathrm{LVH})(\mathrm{G}+/ \mathrm{LVH}+, \mathrm{n}=18)$; and positive genotype without LVH (G+/LVH-, n=23). These groups were compared with matched normal control subjects $(n=30)$. G+/LVH+ patients showed significantly lower septal and lateral Tissue Doppler imaging (TDI)-derived systolic, early and late diastolic mitral annular velocities compared with the controls. In addition, diastolic dyssynchrony index (DDI) was markedly higher in the G+/LVH+ subjects. However, only septal Ea was significantly lower in G+/LVH- subjects in comparison with controls, with no significant difference
\end{abstract}

Correspondence to: Dr Guang Zhi, Department of Cardiology, Chinese People's Liberation Army General Hospital, 28 Fuxing Road, Beijing 100853, P.R. China

E-mail: guangzhi983@yeah.net

Key words: hypertrophic cardiomyopathy, left ventricle hypertrophy, myosin binding protein $\mathrm{C} 3$, diastolic dysfunction in lateral Sa, Ea and Aa, and DDI. In conclusion, the patients in the present study demonstrated a $15 \%$ prevalence of $M y B P C 3$ gene mutations in the Chinese HCM population. $M y B P C 3$ gene mutations may cause regional LV hypertrophic remodeling first and further proceed to global hypertrophic remodeling and myocardial diastolic dysfunction.

\section{Introduction}

Hypertrophic cardiomyopathy (HCM) is a common autosomal dominant cardiac disease characterized by asymmetric left ventricular (LV) hypertrophy (LVH) with heterogeneous morphologic, functional and clinical features (1). Since the pathogenic missense mutation in the $\beta$-myosin heavy chain 7 (MYH7 R403Q) was revealed two decades ago, over 1,400 gene mutations have been identified in $\geq 11$ putative HCM-susceptibility genes (2-4), which predominantly encode for proteins of the thick filament of the cardiac sarcomere. Cardiac myosin-binding protein $\mathrm{C} 3$ (MyBPC3) and myosin heavy chain 7 (MYH7) are, by far, the most common HCM-associated genes with an estimated prevalence of 25-35\% for each gene (5). MyBPC3 is a key constituent of the thick filaments localized to doublets in the $\mathrm{C}$-zone of the A-band of the sarcomere. By binding to myosin, titin and actin, MyBPC 3 contributes to the structural integrity of the cardiac sarcomere and regulates cardiac muscle contractility (6).

Although the mechanisms underlying the correlations between disease-causing genetic mutations and characteristic pathological and morphologic (or phenotypic) features of HCM are unclear, preliminary studies suggest that particular gene abnormalities are associated with specific clinical phenotypes, such as degree of hypertrophy, risk of sudden death, onset of disease and disease penetrance in families (7-9). Mutations in the $M y B P C 3$ gene were found to be responsible for $15-20 \%$ of cases of familial HCM, and were generally associated with mild and age-related penetrance disease (10). However, the prevalence of $M y B P C 3$ mutations 
and the clinical characteristics associated in the Chinese HCM population remain unclear.

The present study is, to the best of our knowledge, the first to identify the prevalence of $M y B P C 3$ gene mutations and the associated characteristic echocardiographic phenotypes in Chinese patients with HCM. To identify these clinical characteristics, cutting-edge echocardiographic techniques, such as 2-dimensional echocardiography (2DE), Tissue Doppler imaging (TDI) and real-time 3-dimensional echocardiography (RT-3DE), were employed.

\section{Materials and methods}

Study population. A total of 48 Chinese adult patients (age, $48 \pm 12$ years) with familial or sporadic HCM were enrolled in the study after informed written consent was obtained. All patients were in sinus rhythm at the time of enrollment and were diagnosed clinically by echocardiography between December 2008 and February 2010 at the General People's Liberation Army Hospital in Beijing, China. A total of 37 patients had a family history of HCM while the other 11 patients did not have confirmed relatives with HCM. The diagnosis of HCM was based on 2DE showing an unexplained maximum left ventricular wall thickness (MLVWT) of $\geq 15 \mathrm{~mm}$ (11) in the absence of other cardiac or systemic disease capable of producing the observed magnitude of hypertrophy (such as systemic hypertension, aortic stenosis and amyloidosis). The family members of index patients with positive $M y B P C 3$ mutations were divided into the following two groups according to whether the patients and their family members met the criteria for diagnosis of HCM from the results of routine echocardiography, as described by McKenna et al (12): Mutation carriers in the LVH group $(\mathrm{G}+/ \mathrm{LVH}+; \mathrm{n}=18)$, and mutation carriers not in the LVH group $(\mathrm{G}+/ \mathrm{LVH}-; \mathrm{n}=23)$. The control group consisted of 30 healthy age- and gender-matched subjects without cardiological disorders.

Genetic study. Venous blood $(3 \mathrm{ml})$ was collected from each subject for $M y B P C 3$ mutation screening. Systematic family screenings of genotyped patients with HCM were performed after identifying $M y B P C 3$ mutations. DNA was extracted from whole blood and stored at $-70^{\circ} \mathrm{C}$. Genomic primer pairs were designed to amplify the whole coding exons of $M y B P C 3$ (35 exons) using Primer BLAST (www. ncbi.nlm.nih.gov/tools/primer-blast/) and Primer Premier 5 software (PREMIER Biosoft, Palo Alto, CA, USA). Nested polymerase chain reaction (PCR) was used to amplify the extracted DNA (Table I). Briefly, for the initial PCR, $0.1 \mu \mathrm{g}$ DNA and primers were used in a $20-\mu 1$ reaction: $2.5 \mu \mathrm{l}$ 10X buffer, $0.5 \mu 12.5 \mathrm{mM}$ dNTPs, $0.4 \mu \mathrm{l}$ of each primer forward $(10 \mu \mathrm{M})$ and reverse $(10 \mu \mathrm{M})$ and $2.5 \mu \mathrm{l}$ of Taq (TaKaRa) $(5 \mathrm{U} / \mu \mathrm{l})$. The target gene was amplified according to the following parameters: Denaturation at $95^{\circ} \mathrm{C}$ for $5 \mathrm{~min}$, 45 cycles of denaturation at $95^{\circ} \mathrm{C}$ for $25 \mathrm{sec}$, annealing at $50^{\circ} \mathrm{C}$ for $60 \mathrm{sec}$ and extension at $72^{\circ} \mathrm{C}$ for $2 \mathrm{~min}$, and a final extension of $5 \mathrm{~min}$ at $72^{\circ} \mathrm{C}$. The second round of PCR was performed using the first-round PCR products in a $20-\mu 1$ reaction: $2.5 \mu \mathrm{l} 10 \mathrm{X}$ buffer, $0.5 \mu 12.5 \mathrm{mM}$ dNTPs, $0.5 \mu 1$ of each primer forward $(10 \mu \mathrm{M})$ and reverse $(10 \mu \mathrm{M})$ and
$2.5 \mu \mathrm{l}$ of Taq (TaKaRa) $(5 \mathrm{U} / \mu \mathrm{l})$. The target gene was amplified according to the following parameters: denaturation at $95^{\circ} \mathrm{C}$ for $3 \mathrm{~min}, 30$ cycles of denaturation at $95^{\circ} \mathrm{C}$ for $30 \mathrm{sec}$, annealing at $55^{\circ} \mathrm{C}$ for $45 \mathrm{sec}$ and extension at $72^{\circ} \mathrm{C}$ for $45 \mathrm{sec}$, and a final extension of $2 \mathrm{~min}$ at $72^{\circ} \mathrm{C}$. Following PCR amplification, PCR products were analyzed by direct sequencing on an ABI PRISM 3130 DNA Analyzer with BigDye Terminator chemistry (version 3.1; Applied Biosystems; Thermo Fisher Scientific, Inc., Waltham, MA, USA). The fluorophore used was SYBR green (Applied Biosystems; Thermo Fisher Scientific, Inc.). The $2^{-\Delta \Delta c q}$ method was used to quantify the results (13). All results were repeated four independent experiments. The relative level of mRNA was calculated by the comparative CT method with GAPDH mRNA as the housekeeping gene.

For every sequence variant detected, a cohort of 200 ethnically matched control subjects were screened by using the same methodology. Conservation of residues was determined by Homologene (www.ncbi.nlm.nih.gov/homologene) by multiple alignment of orthologues in various species, including Homo sapiens, Pan troglodytes, Canis lupus, Bos taurus, Mus musculus, Rattus norvegicus, Gallus gallus and Danio rerio. A variant was considered a mutation if it showed co-segregation with affected members in the family, was not present in the 200 healthy adult controls, and if the mutated residue was conserved among species.

Clinical evaluation. Index patients and their relatives were evaluated for family history, age, gender, body surface area and clinical symptoms. They also underwent 12-lead electrocardiography, 2DE, TDI, and 3DE.

2-DE. 2DE images were acquired with a commercially available ultrasound system (Acuson Sequoia 512; Siemens AG, Munich, Germany) equipped with a 4V1c transducer (1-4 MHz). LV end-diastolic diameter (LVEDD) and LV end-systolic diameter (LVESD) were measured using M-mode and 2D images obtained from parasternal long-axis views. The severity and distribution of LVH was assessed in the parasternal short-axis plane at the mitral valve and papillary muscle levels. MLVWT was regarded as the greatest thickness at any site in the LV wall (14). Patients were classified as having obstructive HCM when the LV outflow tract gradient was $\geq 30 \mathrm{mmHg}$ (15). The mitral early (E-wave) and late (A-wave) filling velocities ratio (E/A), and the E-wave velocity deceleration time (DT) were measured by pulsed-wave Doppler. TDI was performed by placing the sample volume at the side of the basal septal and lateral wall in the apical 4-chamber view. The mitral annular systolic ( $\mathrm{Sa})$, and early (Ea) and late (Aa) diastolic velocities were recorded at late expiration in the pulsed-wave Doppler mode. Diastolic function was subsequently graded 0 to 3 , as previously described (16): Grade 0 (normal relaxation): DT >140 msec, E/A ratio $>1$ and septal E/Ea ratio $<8$; Grade 1 (impaired relaxation): $\mathrm{DT}>140 \mathrm{msec}, \mathrm{E} / \mathrm{A}$ ratio $<0.75$ and $\mathrm{E} / \mathrm{Ea}$ ratio $<8$; Grade 2 (pseudo-normal filling): DT >140 msec, $1<\mathrm{E} / \mathrm{A}$ ratio $<1.5$ and $\mathrm{E} /$ Ea ratio $>15$, and systolic/diastolic pulmonary vein ratio $<1$; Grade 3 (restrictive filling): E/A ratio $\geq 1.5$, DT $<140 \mathrm{msec}$, E/Ea ratio $>15$, and systolic/diastolic pulmonary vein ratio $<1$. 
3-DE. 3DE images were obtained with a commercially available ultrasound system (Acuson SC2000; Siemens AG) equipped with a 4Z1c transducer (2-4 MHz). This system has $15-17 \mathrm{~cm}$ detectable depth, $90 \times 90^{\circ}$ scanning angle, and $>20$ frames/sec volume rate. Electrocardiogram (ECG) images were obtained in the left lateral decubitus position. The 3D data sets were analyzed offline using the Left Ventricular Analysis System (Siemens Medical Solutions, Inc., Malvern, PA, USA). Various sequences of the endocardium were automatically signed and manually revised. The LV was automatically divided into 17 segments. Diastolic dyssynchrony index (DDI), as a mechanical dyssynchrony parameter used in the software, was derived from the standard deviation of the regional end-diastolic peak volume times of the 17-segment model and represented the mechanical dyssynchrony of a ventricle. End-diastolic synchrony with the DDI index was evaluated using the following equation:

$$
\mathrm{DDI}=\sqrt{\frac{1}{N-1} \sum_{i=1}^{N}\left(t_{i}-\bar{t}\right)}
$$

Where $t_{i}$ represents regional relaxation times, and $t$ represents the mean regional relaxation times.

The images were stored by adopting the P-P interval in the ECG to acquire a harmonized standard. Then, the sampling points for every segment were automatically located in the maximum volume and the DDI was automatically calculated by the software.

Statistical analysis. Data were expressed as mean \pm standard deviation, data was analyzed using the Chi-square test for qualitative data and one-way analysis of variance or Wilcoxon rank sum test for quantitative data, followed by Student-Newman-Keuls multiple range test for multiple comparisons, and variables were analyzed by post-hoc tests between the control group and the G+/LVH+ or G+/LVHgroups. $\mathrm{P}<0.05$ was considered to indicate a statistically significant difference. All statistical analyses were performed using the SPSS version 16 for Windows (SPSS, Inc., Chicago, IL, USA).

\section{Results}

Genetic study. Nine mutations in the $M y B P C 3$ gene were identified in $7 / 48$ cases (15\%), with two patients having digenic mutations in the same gene. Specifically, there are 7 missense mutations (c.2541C>G/p.Y847X, c.2526C > G/p.Y842X, c. $2527 \mathrm{G}>\mathrm{T} / \mathrm{p} . \mathrm{Y} 843 \mathrm{X}$, c.706A>G/p.S236G, c.772G $>\mathrm{A} / \mathrm{p}$. E258K, c.2971G>A/p.V991M and c.3272A>G/p.D1091G), and 2 synonymous mutations (c.2118T $>$ C/p.G706G and c.2025G>A/p.G675). Among them, four mutations were novel while the other five mutations had been previously published (Table II). In addition, all the index patients with these novel mutations have a familial HCM history. Systematic genetic screenings and echocardiographic characterization of these patients showed that 18 subjects had $M y B P C 3$ mutations and HCM phenotype (G+/LVH+ group), and the other 23 subjects had $M y B P C 3$ mutations only (G+/LVH- group) (Table III). All mutations located in exon regions were concentrated in 5 myosin domains, C1, C5, C6, C8 and C9 (Fig. 1).
Clinical characteristics. The clinical variables of subjects enrolled in this study at the baseline are displayed in Table IV. There was no significant difference in blood pressure or heart rate among the three groups. However, by comparing with the other two groups, the $\mathrm{G}+/ \mathrm{LVH}+$ population was significantly older $(\mathrm{P}<0.0001)$ and had more males than females. All patients were symptomatic at the first presentation; $90 \%$ of them had mild symptoms (functional New York Heart Association [NYHA] class). Patients with HCM were managed primarily through medication ( $\beta$-blockers and calcium channel blockers). Diastolic function was normal (grade 0) in all controls and all G+/LVH- subjects. The majority of $\mathrm{G}+/ \mathrm{LVH}+$ subjects had grades 1 to 2 diastolic dysfunction and asymmetrical septal hypertrophy (14/18).

Echocardiographic features. The results of the echocardiographic analysis are displayed in Table V. As expected, maximal LV wall thickness and interventricular septal thickness (IVS) were higher in the G+/LVH+ subjects compared with control $(\mathrm{P}<0.05)$ and $\mathrm{G}+/ \mathrm{LVH}$-subjects. In addition, the left atrial dimension was significantly higher in the $\mathrm{G}+/ \mathrm{LVH}+$ subjects compared with the control. There were no significant differences in LVEDD, LVESD and LV ejection fraction among the three groups.

In the $\mathrm{G}+/ \mathrm{LVH}+$ group, velocity parameters including septal $\mathrm{Sa}$, Ea and $\mathrm{Aa}$, and lateral $\mathrm{Sa}$ and $\mathrm{Ea}$ velocities were significantly lower compared with their counterparts in the control group $(\mathrm{P}<0.05)$. However, there was no significant difference in lateral Aa velocity between the G+/LVH+ and control groups. In the G+/LVH- group, only the septal Ea peak velocity (rather than septal $\mathrm{Sa}$ and $\mathrm{Aa}$, and lateral $\mathrm{Sa}$, Ea and Aa velocities) was significantly lower $(\mathrm{P}<0.0001)$ compared with the control group (Fig. 2). Fig. 2 shows the comparison between the G+/LVH- or G+/LVH+ group and the control. There was no significant difference in septal $\mathrm{Sa}$ and $\mathrm{Aa}$, and lateral $\mathrm{Sa}, \mathrm{Ea}$ and $\mathrm{Aa}$ velocities between the G+/LVH- and control groups. The DT was significantly increased in the $\mathrm{G}+/ \mathrm{LVH}+$ and $\mathrm{G}+/ \mathrm{LVH}$-groups compared with the control group $(\mathrm{P}<0.0001)$, although there was no significant difference in E/A ratios among the three groups.

According to the 3DE images, the 17 segmental curves, divided according to the recommendations of the Joint Committee of the American Heart Association (17), were smooth and regular for the controls, whereas the curves for HCM subjects were dyssynchronous (Fig. 3). A significant increase in DDI was found in the $\mathrm{G}+/ \mathrm{LVH}+$ group $(\mathrm{P}<0.0001)$. However, no difference was observed between controls and the G+/LVH- group. This implies that the diastolic dyssynchrony may be a predominant cause of the diastolic dysfunction in patients with HCM.

\section{Discussion}

HCM is a primary myocardial disorder marked by genotypic and phenotypic heterogeneity (18). More than 200 different gene mutations have been reported for HCM, and the disease is typically caused by single heterozygous mutations in the gene encoding sarcomere proteins. Mutations in $M y B P C 3$ are the most common type found in patients with HCM. Identification of specific $M y B P C 3$ mutations may give 
Table I. Primer sequences.

\begin{tabular}{|c|c|c|}
\hline Gene & Forward primer $\left(5^{\prime}-3^{\prime}\right)$ & Reverse primer $\left(5^{\prime}-3^{\prime}\right)$ \\
\hline Exon1 & GAGGCAGATAAGCAGAGCCT' & CССТCAAGAACTCССТССТ \\
\hline Exon2 & GCATAGAAAGTGCTAGCACA & GGAAGGCTGATCAGGATCTT \\
\hline Exon3 & GACAGCCATGGCAGACTTT & TTGAGACCTGCCCTGGACA \\
\hline Exon4 & CCTTTGCTCACAGGGTCAA & CATTTGCCCTTGAACCACT \\
\hline Exon5 & CCATTGGCCTCTTCGTGAT & CATTTGCCCTTGAACCACT \\
\hline Exon6 & CCCAGTCTCCTTTAAGGGT & GAGGCATCCTCCTTAGTGTT \\
\hline Exon7 & GAATGGGCAAGTCTGTGAAT & CTCAGTATCCTCACCTGCCT \\
\hline Exon8 & GGCAGGTGAGGATACTGAGT & GAAAGGGACACTAGCCAGAT \\
\hline Exon9 & CAATCTGGCTAGTGTCCCTT & GACTGTTGACGGGACATAAT \\
\hline Exon11 & GGTGGCCATACCTCTCATGT & TAGGATCTCCCACACGTCCT \\
\hline Exon12 & GCTACAGCTCCTTGGTCCT & GTGTAGGGAAGGGCTAGCCT \\
\hline Exon13 & GGTGCTCAGCCTTTCAGAA & CGAGTCAGAGATACGCATGT \\
\hline Exon15 & GCAGCTTTCCTGCCACTTC & GTGAGCATGAGGGTTGGCT \\
\hline Exon16 & CCTGAGGATGTGGGAACCT & CAAGTGCTGTGGCCTCTTCT \\
\hline Exon17 & GCGCAAGTCAAATGGTGAGT & CAAGCCCTAAAGCCTCATGT \\
\hline Exon18 & CTCAGACACTTGAGGTTCCT & СТCTGTCTCCATCTCAGTCT \\
\hline Exon19 & CCAACAAGCCAGGACAAGGT & CGGGAAAGTGAGCAGAACCA \\
\hline Exon 20 & CCAACAAGCCAGGACAAGGT & CGGGAAAGTGAGCAGAACCA \\
\hline Exon21 & СTCTCCCGTTTCTCTGAACT & GGTTCCACACACCCATCTTA \\
\hline Exon 22 & CTGAGTCAGCTCCTCTGCT & TGATGGCCATCAGCACACT \\
\hline Exon 23 & GAACTAGATGCTGACGTGGA & GTTTGTCGAGTGGCTGAAT \\
\hline Exon24 & GCGGTTAGTTGGAGTGGGA & CATCCACCGGTAGCTCTTCT \\
\hline Exon 25 & GGACTCCTGCACAGTACAGT & CCTGCAGAGCACCTGCTATT \\
\hline Exon26 & CTATGTGACCAGTGGGCAGT & CTCTGGGTGTCCTCAACTTT \\
\hline Exon 27 & GTCAGTGGTGACACAGCCT & GGGTCTTGTGACTGCACAAA \\
\hline Exon 28 & GTGTTAGCAGGAGCTAAAGG & CTGGATGGGAACAACACACT \\
\hline Exon29 & GAGTGATCCAGGTTCAGGGT & GGAAAATGTGAGCTGTGGGT \\
\hline Exon30 & CCAACCCACAGCTCACATTT & GAGGACAGTGAAGGGTAGCT \\
\hline Exon31 & GCTGATCTGAATCCCTCCAT & CTGGTTGGAAGAATGAGGGT \\
\hline Exon32 & TCTCGGTACCAAGTCCTGT & GGAACCAAGAGTGAGTACCA \\
\hline Exon33 & СTCTCAGCCTGGATGGCTT & CCGAGGACAACGGAGCAAA \\
\hline Exon34 & GCAATAGCTTCCAGAAGGCT & ССТСССATTTACTGATGGCT \\
\hline Exon35 & CATCAGTAAATGGGAGGCTG & GGCACACCGAAATTGAGAA \\
\hline
\end{tabular}

Table II. Mutations in the $M y B P C 3$ gene.

\begin{tabular}{lccccc}
\hline Family & Type & Exon & $\begin{array}{c}\text { Nucleotide } \\
\text { change }\end{array}$ & $\begin{array}{c}\text { Amino acid } \\
\text { change }\end{array}$ & Novelty \\
\hline H104 & Missense & E6 & c.706A $>$ G & p.S236G & Previously published \\
H31 & Missense & E6 & c.772G $>$ A & p.E258K & Previously published \\
H09 & Missense & E25 & c.2541C>G & p.Y847X & Previously published \\
H35 & Missense & E25 & c.2526C $>$ G & p.Y842X & Previously published \\
H108 & Missense & E25 & c.2527G $>$ T & p.Y843X & Previously published \\
H104 & Synonymous & E22 & c.2118T>C & p.G706G & Novel \\
H106 & Synonymous & E21 & c.2025G $>$ A & p.G675G & Novel \\
H35 & Missense & E28 & c.2971G $>$ A & p.V991M & Novel \\
H107 & Missense & E30 & c.3272A $>$ G & p.D1091G &
\end{tabular}

clinicians insight into the genetic course of the disease. Various reports have indicated that $M y B P C 3$ mutations are present in $14.5-26 \%$ of patients with HCM [18.2\% at the Mayo Clinic, $14.5 \%$ at Harvard Medical School, 26\% in France, 
Table III. Baseline characteristics of mutations in the $M y B P C 3$ gene.

\begin{tabular}{|c|c|c|c|c|c|c|c|}
\hline Family & Gender & $\begin{array}{c}\text { Age } \\
\text { (years) }\end{array}$ & Mutation & Exon & $\begin{array}{c}\text { LVH } \\
\text { distribution }\end{array}$ & $\begin{array}{c}\text { G+/LVH+ } \\
(\mathrm{n}=18)\end{array}$ & $\begin{array}{c}\text { G+/LVH- } \\
(n=23)\end{array}$ \\
\hline $\mathrm{H} 104$ & $\mathrm{M}$ & 55 & $\begin{array}{l}\text { c. } 706 \mathrm{~A}>\mathrm{G} \\
\text { c. } 2118 \mathrm{~T}>\mathrm{C}\end{array}$ & $\mathrm{E} 6+\mathrm{E} 22$ & $\begin{array}{l}\text { Mid septum and } \\
\text { apical }\end{array}$ & 2 & 2 \\
\hline H31 & M & 43 & c. $772 \mathrm{G}>\mathrm{A}$ & E6 & Mid septum & 4 & 6 \\
\hline H09 & $\mathrm{F}$ & 45 & c. $2541 \mathrm{C}>\mathrm{G}$ & E25 & Mid septum & 4 & 7 \\
\hline H35 & $\mathrm{M}$ & 56 & $\begin{array}{l}\text { c. } 2526 \mathrm{C}>\mathrm{G} \\
\text { c. } 2971 \mathrm{G}>\mathrm{A}\end{array}$ & $\mathrm{E} 25+\mathrm{E} 28$ & $\begin{array}{l}\text { Mid septum and } \\
\text { apical }\end{array}$ & 2 & 2 \\
\hline H108 & $\mathrm{M}$ & 55 & c. $2527 \mathrm{G}>\mathrm{T}$ & E25 & Basal-mid septum & 2 & 2 \\
\hline H106 & $\mathrm{F}$ & 35 & c. $2025 \mathrm{G}>\mathrm{A}$ & E21 & Basal-mid septum & 1 & - \\
\hline H107 & M & 44 & c. $3272 \mathrm{~A}>\mathrm{G}$ & E30 & Apical & 3 & 4 \\
\hline
\end{tabular}

LVH, left ventricular hypertrophy; G, genotype; M, male; F, female.

Table IV. Phenotypic characteristics of patients.

\begin{tabular}{|c|c|c|c|c|}
\hline Characteristic & $\begin{array}{l}\mathrm{G}+/ \mathrm{LVH}+ \\
\quad(\mathrm{n}=18)\end{array}$ & $\begin{array}{l}\mathrm{G}+/ \mathrm{LVH}- \\
(\mathrm{n}=23)\end{array}$ & $\begin{array}{l}\text { Controls } \\
(n=30)\end{array}$ & P-value \\
\hline Age, years & $48 \pm 12^{\mathrm{a}}$ & $38 \pm 10^{\mathrm{a}}$ & $40 \pm 11$ & $<0.001$ \\
\hline Men, n $(\%)$ & $11(61 \%)$ & $16(69 \%)$ & $19(63 \%)$ & 0.460 \\
\hline Body surface area, $\mathrm{m}^{2}$ & $1.8 \pm 0.2$ & $1.6 \pm 0.1$ & $1.7 \pm 0.1$ & 0.210 \\
\hline Systolic blood pressure & $125 \pm 16$ & $120 \pm 10$ & $122 \pm 9$ & 0.090 \\
\hline Diastolic blood pressure & $74 \pm 9$ & $70 \pm 9$ & $73 \pm 8$ & 0.140 \\
\hline Heart rate, beats/min & $68 \pm 10$ & $71 \pm 10$ & $67 \pm 10$ & 0.580 \\
\hline NYHA function class (\%) & $2(11 \%)$ & 0 & 0 & $<0.001$ \\
\hline Dyspnea, n (\%) & $11(61 \%)$ & 0 & 0 & $<0.001$ \\
\hline Angina, n (\%) & $7(39 \%)$ & 0 & 0 & $<0.001$ \\
\hline$\beta$-blockers, n (\%) & $10(56 \%)$ & 0 & 0 & $<0.001$ \\
\hline $\begin{array}{l}\text { LVOT obstruction, } \mathrm{n}(\%) \\
\text { (pressure gradient } \geq 30 \mathrm{mmHg} \text { ) }\end{array}$ & $5(28 \%)$ & 0 & 0 & $<0.001$ \\
\hline \multicolumn{5}{|l|}{ Distribution of HCM } \\
\hline Asymmetric septum, n (\%) & $14(78 \%)$ & 0 & 0 & - \\
\hline Symmetric septum, n (\%) & 0 & 0 & 0 & - \\
\hline Apical HCM, n (\%) & $4(22 \%)$ & 0 & 0 & - \\
\hline \multicolumn{5}{|l|}{ Grade of diastolic function } \\
\hline Grade 0 & 0 & 23 & 30 & 0.009 \\
\hline Grade 1 & 6 & 0 & 0 & $<0.001$ \\
\hline Grade 2 & 8 & 0 & 0 & $<0.001$ \\
\hline Grade 3 & 4 & 0 & 0 & $<0.001$ \\
\hline
\end{tabular}

${ }^{\mathrm{a}} \mathrm{P}<0.05$ vs. controls. Data are presented as the mean \pm standard deviation. NYHA, New York Heart Association; HCM, hypertropic cardiomyopathy; LVOT, left ventricular outflow tract.

$18 \%$ in Germany, $21.7 \%$ in Sweden and 24\% in Finland (19)]. However, the prevalence of $M y B P C 3$ mutations in Chinese patients with HCM has, to the best of our knowledge, not been investigated. The present study revealed that there is a $15 \%$ prevalence of $M y B P C 3$ mutations in Chinese patients with $\mathrm{HCM}$, which is within the range reported above. In addition, double $M y B P C 3$ mutations were identified in two families, which accounts for $3 \%$ of the multiple mutation rate, similar to as previously described $(19,20)$. These data indicate that $M y B P C 3$ mutations may be the most common genetic cause of HCM in patients in China.

MyBPC3 is a structural and regulatory protein found in the sarcomere. The $\mathrm{C} 0$ and $\mathrm{C} 1$ domains at the $\mathrm{N}$-terminus are primarily responsible for sarcomere regulation and include 
Table V. 2-Dimensional echocardiography characteristics of patients.

\begin{tabular}{|c|c|c|c|c|}
\hline Characteristic & $\mathrm{G}+/ \mathrm{LVH}+(\mathrm{n}=18)$ & G+/LVH- $(\mathrm{n}=23)$ & Controls $(n=30)$ & P-value \\
\hline Maximal LV wall thickness, $\mathrm{cm}$ & $2.0 \pm 0.3^{\mathrm{a}}$ & $0.9 \pm 0.4$ & $0.8 \pm 0.2$ & $<0.001$ \\
\hline IVS, $\mathrm{cm}$ & $1.9 \pm 0.5^{\mathrm{a}}$ & $1.0 \pm 0.2^{\mathrm{a}}$ & $0.8 \pm 0.3$ & $<0.001$ \\
\hline LPW, cm & $0.8 \pm 0.2^{\mathrm{a}}$ & $0.7 \pm 0.1$ & $0.7 \pm 0.1$ & $<0.001$ \\
\hline IVS/LPW & $2.4 \pm 0.4^{\mathrm{a}}$ & $1.4 \pm 0.3^{\mathrm{a}}$ & $1.1 \pm 0.2$ & $<0.001$ \\
\hline LVEDD, cm & $4.6 \pm 0.8$ & $4.7 \pm 0.6$ & $4.6 \pm 0.7$ & 0.720 \\
\hline LVESD, cm & $3.2 \pm 0.7$ & $3.1 \pm 0.6$ & $3.0 \pm 0.5$ & 0.680 \\
\hline LV ejection fraction, $\%$ & $62.2 \pm 6.8$ & $64.0 \pm 4.9$ & $62.9 \pm 5.6$ & 0.200 \\
\hline $\mathrm{LA}, \mathrm{cm}$ & $40.0 \pm 3.3^{\mathrm{a}}$ & $35.0 \pm 2.1$ & $33 \pm 2.6$ & $<0.001$ \\
\hline $\mathrm{E} / \mathrm{A}$ ratio & $1.4 \pm 0.7$ & $1.3 \pm 0.6$ & $1.4 \pm 0.6$ & 0.060 \\
\hline DT, msec & $169.7 \pm 49.0^{\mathrm{a}}$ & $157.0 \pm 47.0^{\mathrm{a}}$ & $140.0 \pm 44.0$ & 0.010 \\
\hline Septal Sa, cm/sec & $8.0 \pm 1.5^{\mathrm{a}}$ & $9.8 \pm 1.3$ & $10.1 \pm 1.0$ & $<0.001$ \\
\hline Septal Ea, cm/sec & $6.2 \pm 2.3^{\mathrm{a}}$ & $8.5 \pm 1.7^{\mathrm{a}}$ & $11.4 \pm 2.1$ & $<0.001$ \\
\hline Septal Aa, cm/sec & $7.8 \pm 2.5^{\mathrm{a}}$ & $11.4 \pm 3.1$ & $10.6 \pm 2.3$ & $<0.001$ \\
\hline Septal E/Ea ratio & $13.4 \pm 3.0^{\mathrm{a}}$ & $6.6 \pm 2.4^{\mathrm{a}}$ & $5.2 \pm 2.1$ & $<0.001$ \\
\hline Lateral $\mathrm{Sa}, \mathrm{cm} / \mathrm{sec}$ & $8.4 \pm 2.2^{\mathrm{a}}$ & $10.9 \pm 2.6$ & $12.2 \pm 3.1$ & $<0.001$ \\
\hline Lateral Ea, cm/sec & $9.1 \pm 2.3^{\mathrm{a}}$ & $15.9 \pm 2.1$ & $17.3 \pm 1.9$ & $<0.001$ \\
\hline Lateral Aa, cm/sec & $9.8 \pm 3.5$ & $10.9 \pm 2.8$ & $11.6 \pm 2.9$ & 0.140 \\
\hline Lateral E/Ea ratio & $8.1 \pm 3.6^{\mathrm{a}}$ & $5.7 \pm 2.3$ & $6.4 \pm 2.8$ & $<0.001$ \\
\hline Average $\mathrm{Sa}, \mathrm{cm} / \mathrm{sec}$ & $8.1 \pm 1.8^{\mathrm{a}}$ & $10.4 \pm 2.1$ & $11.2 \pm 2.0$ & $<0.001$ \\
\hline Average Ea, cm/sec & $7.7 \pm 2.9^{a}$ & $12.6 \pm 2.0^{\mathrm{a}}$ & $14.5 \pm 1.8$ & $<0.001$ \\
\hline DDI & $9.1 \pm 3.4^{\mathrm{a}}$ & $5.1 \pm 1.2$ & $4.7 \pm 1.6$ & $<0.001$ \\
\hline
\end{tabular}

${ }^{a} \mathrm{P}<0.05$ vs. controls. Data are presented as the mean \pm standard deviation. G, genotype; LV, left ventricular; LA, left atrial; E, mitral early filling velocity; A, mitral late filling velocity; LVH, LV hypertrophy; IVS, interventricular septal thickness; LPW, left posterior wall; LVEDD, LV end-diastolic dimension; LVESD, LV end-systolic dimension; E/A, E-wave/A-wave; DT, deceleration time; Sa, systolic; Ea, mitral annular early diastolic velocity; DDI, diastolic dyssynchrony index.
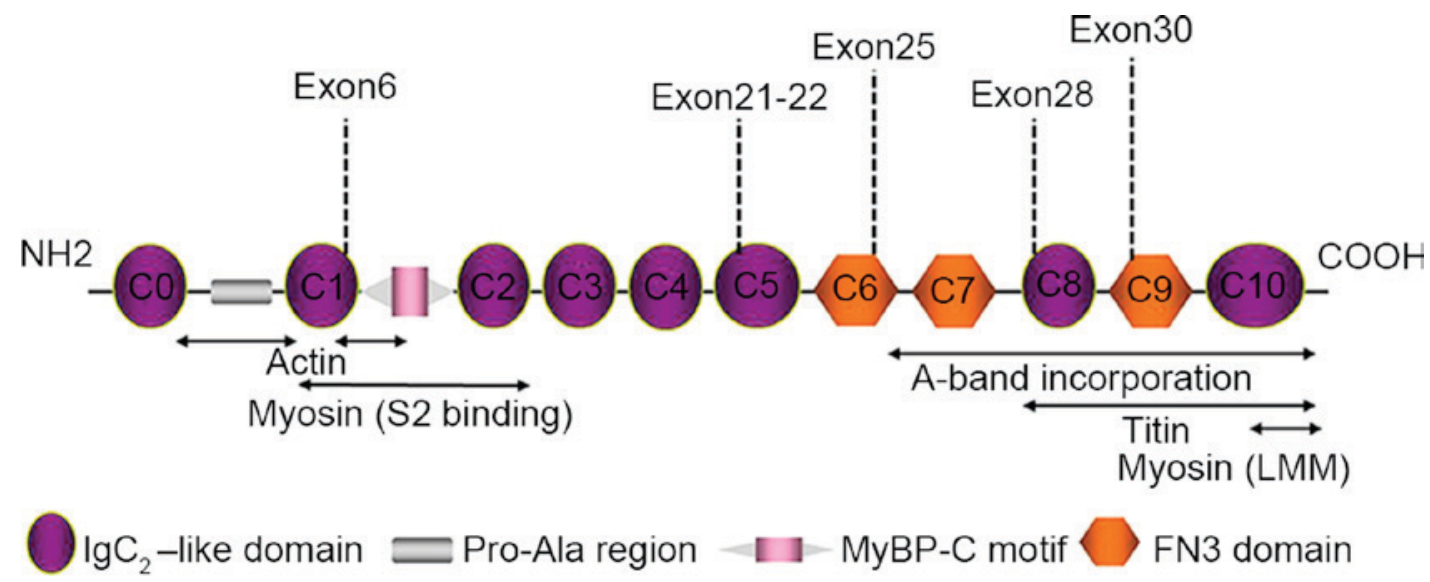

Figure 1. Myosin-binding protein C secondary structure with locations of exonic mutations associated with hypertrophic cardiomyopathy. MyBP-C, myosin-binding protein C3; LMM, light meromyosin.

a Pro-Ala-rich region and a myosin binding domain, which is a target of post-translational modifications. The $\mathrm{C} 5-\mathrm{C} 10$ domains at the $\mathrm{C}$-terminus participate in binding myosin and titin, and are necessary for MyBPC3 stability and sarcomere organization $(21,22)$. The novel mutations identified in the present study are located at $\mathrm{C} 5, \mathrm{C} 8$ and $\mathrm{C} 9$, suggesting that these mutations may affect myocardial function through changing MyBPC3 protein stability and sarcomere structure.
Diastolic dysfunction has been documented as the early sign of HCM preceding $\mathrm{LVH}$ in human and animal models harboring HCM disease causing genetic mutations (23-26). Previous studies have demonstrated that nonhypertrophied regions of LV may contribute to diastolic dysfunction in patients with HCM (27). Diastolic dysfunction was observed in all patients with HCM with $M y B P C 3$ gene mutations in the present study, along with significantly increased septal 

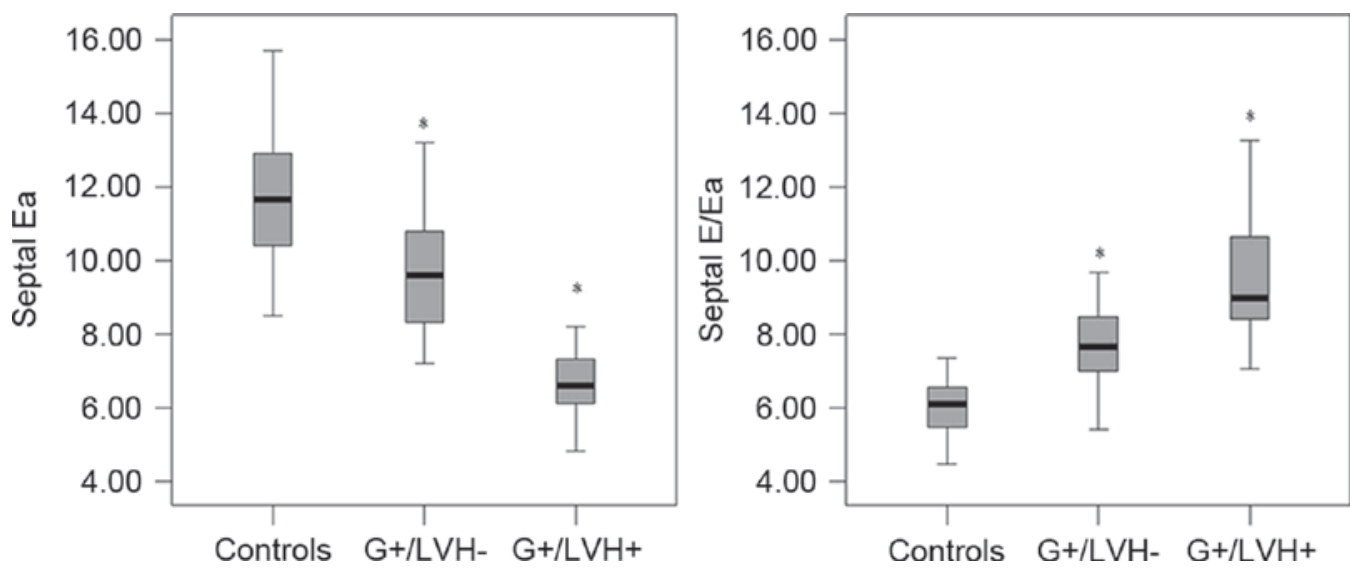

Figure 2. 2-Dimensional boxplots of septal Ea and E/Ea ratio values within groups. The left panel shows decreased septal Ea in G+/LVH+ and G+/LVHgroups. The right panel shows increased septal E/Ea ratio in $\mathrm{G}+/ \mathrm{LVH}+$ and $\mathrm{G}+/ \mathrm{LVH}$-groups. LVH+, patients with typical $\mathrm{LVH}$; $\mathrm{G}+/ \mathrm{LVH}-, \mathrm{LVH}-\mathrm{free}$ mutation carriers. Data are presented as the mean \pm standard deviation. "P<0.05 vs. controls. G, genotype; LVH, left ventricular hypertrophy; E, E-wave; Ea, early.
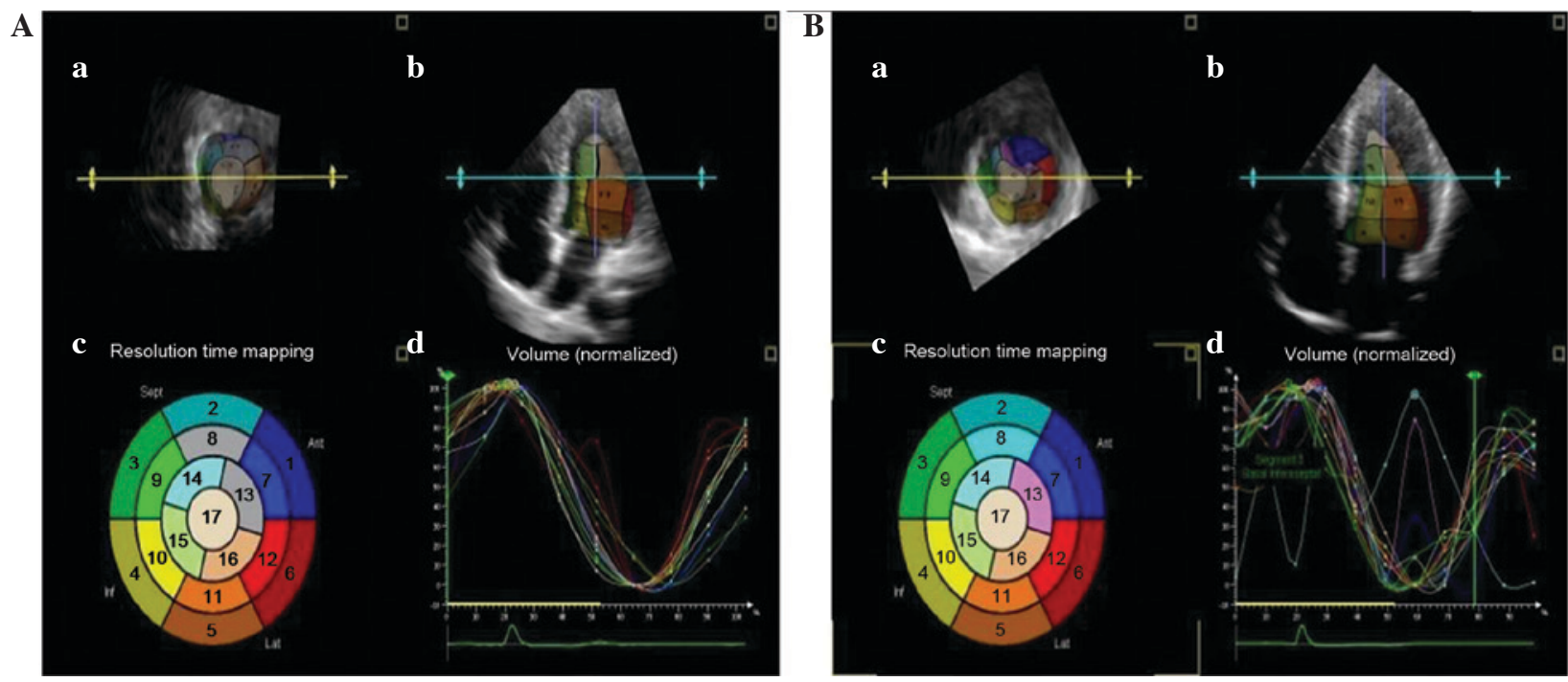

Figure 3. Example of the 17-segment normalized volume-time curves in relaxation time mapping derived from three-dimensional echocardiography. The left ventricular chamber was divided into 17 segments. The lower left image is a two-dimensional plane of 17 segments assigned different colors. The graph on the lower right shows the curve displays for volume (\%) / time (ms, \%), normalized to their individual maximum, for the 17 segments. The sampling points (color circles in curves) for every segment corresponded with the maximum volume (end diastole) in relaxation time mapping. Every curve represents volume change in the related segment that varied with the cardiac cycle period. Volume-time curves are showed on the right. (A) 17-segment curves are smooth and regular, reflecting the low diastolic dyssynchrony index (DDI) in the control subjects. (Aa) 3D image of left ventricular apex represented by 17 -segment model. (Ab) 3D image of left ventricle represented by 17-segment model. (Ac) 17-segment model of left ventricle (AHA) and (Ad) Normalized volume-time curves of 17 segment in diastole. (B) 17-segment curves are dyssynchronous, reflecting the high DDI in patients with hypertrophy cardiomyopathy. (Ba) 3D image of left ventricular apex represented by 17-segment model. (Bb) 3D image of left ventricle represented by 17-segment model. ( $\mathrm{Bc}$ ) 17-segment model of left ventricle (AHA) and (Bd) Normalized volume-time curves of 17 segment in diastole. ${ }^{*} \mathrm{P}<0.001$ vs. controls.

and lateral E/Ea ratio and significantly increased DDI values. E/Ea ratio reflects the filling pressure in patients with HCM by TDI, and the higher ratio reflects a higher severity of symptoms (28). The DDI value is a mechanical dyssynchrony parameter in $3 \mathrm{DE}$; the higher the value, the more severe the diastolic dyssynchrony (29). Furthermore, the present study showed that regional remodeling of LV may be independent and occur prior to global LVH. Increased septal E/Ea ratio was observed in the G+/LVH- group in the absence of lateral E/Ea ratio change, and increased IVS and LPW ratio in $\mathrm{G}+/ \mathrm{LVH}$ - group was observed, which suggests local remodeling, consistent with previous studies which showed histological abnormalities in the absence of significant LVH (30). In addition, no significant change in DDI value was observed in the $\mathrm{G}+/ \mathrm{LVH}$ - group, indicating that regional myocardial function abnormalities were not serious enough to affect global LV diastolic function. These findings suggest that regional hypertrophic remodeling proceeds myocardial dysfunction in patients with $M y B P C 3$ mutations. However, detailed prospective studies are required to better understand the chronology of the development of HCM caused by $M y B P C 3$ mutations.

In conclusion, the present study revealed a $15 \%$ prevalence of $M y B P C 3$ gene mutations in the Chinese HCM population. $M y B P C 3$ gene mutation caused regional LV hypertrophic remodeling first and further proceeded to global hypertrophic remodeling and myocardial diastolic dysfunction. Combined applications of 2DE, TDI and 3DE are a feasible 
way to detect early myocardial remodeling and myocardial dysfunction in patients with genetic predisposition.

\section{References}

1. Elliott P and McKenna WJ: Hypertrophic cardiomyopathy. Lancet 363: 1881-1891, 2004.

2. Landstrom AP and Ackerman MJ: Mutation type is not clinically useful in predicting prognosis in hypertrophic cardiomyopathy. Circulation 122: 2441-2449; discussion 2450, 2010.

3. Watkins H, Rosenzweig A, Hwang DS, Levi T, McKenna W, Seidman CE and Seidman JG: Characteristics and prognostic implications of myosin missense mutations in familial hypertrophic cardiomyopathy. N Engl J Med 326: 1108-1114, 1992.

4. Maron BJ, Maron MS and Semsarian C: Genetics of hypertrophic cardiomyopathy after 20 years: Clinical perspectives. J Am Coll Cardiol 60: 705-715, 2012.

5. Wang L, Seidman JG and Seidman CE: Narrative review: Harnessing molecular genetics for the diagnosis and management of hypertrophic cardiomyopathy. Ann Intern Med 152: 513-520, 2010

6. Flavigny J, Robert P, Camelin JC, Schwartz K, Carrier L and Berrebi-Bertrand I: Biomolecular interactions between human recombinant beta-MyHC and $\mathrm{cMyBP}-\mathrm{Cs}$ implicated in familial hypertrophic cardiomyopathy. Cardiovasc Res 60: 388-396, 2003.

7. Kimura A: Molecular etiology and pathogenesis of hereditary cardiomyopathy. Circ J 72 (Suppl A): A-38-A48, 2008.

8. Ho CY, Lever HM, DeSanctis R, Farver CF, Seidman JG and Seidman CE: Homozygous mutation in cardiac troponin T: Implications for hypertrophic cardiomyopathy. Circulation 102 1950-1955, 2000.

9. Richard P, Charron P, Leclercq C, Ledeuil C, Carrier L, Dubourg O, Desnos M, Bouhour JB, Schwartz K, Daubert JC, et al: Homozygotes for a R869G mutation in the beta-myosin heavy chain gene have a severe form of familial hypertrophic cardiomyopathy. J Mol Cell Cardiol 32: 1575-1583, 2000 .

10. Maron BJ, Niimura H, Casey SA, Soper MK, Wright GB, Seidman JG and Seidman CE: Development of left ventricular hypertrophy in adults in hypertrophic cardiomyopathy caused by cardiac myosin-binding protein $\mathrm{C}$ gene mutations. J Am Coll Cardiol 38: 315-321, 2001.

11. Wigle ED, Sasson Z, Henderson MA, Ruddy TD, Fulop J, Rakowski H and Williams WG: Hypertrophic cardiomyopathy. The importance of the site and the extent of hypertrophy. A review. Prog Cardiovasc Dis 28: 1-83, 1985.

12. McKenna WJ, Spirito P, Desnos M, Dubourg O and Komajda M: Experience from clinical genetics in hypertrophic cardiomyopathy: Proposal for new diagnostic criteria in adult members of affected families. Heart 77: 130-132, 1997.

13. Livak KJ and Schmittgen TD: Analysis of relative gene expression data using real-tie quantitative PCR and the 2(-Delta Delta C(T)) Method. Methods 25: 402-408, 2001

14. Spirito P, Bellone P, Harris KM, Bernabo P, Bruzzi P and Maron BJ: Magnitude of left ventricular hypertrophy predicts the risk of sudden death in hypertrophic cardiomyopathy. N Engl J Med 342: 1778-1785, 2000.

15. Maron BJ, McKenna WJ, Danielson GK, Kappenberger LJ, Kuhn HJ, Seidman CE, Shah PM, Spencer WH III, Spirito P, Ten Cate FJ and Wigle ED; Task Force on Clinical Expert Consensus Documents, American College of Cardiology; Committee for Practice Guidelines, European Society of Cardiology: American college of cardiology/European society of cardiology clinical expert consensus document on hypertrophic cardiomyopathy. A report of the American college of cardiology foundation task force on clinical expert consensus documents and the European society of cardiology committee for practice guidelines. J Am Coll Cardiol 42: 1687-1713, 2003.
16. McKenna WJ, Spirito P, Desnos M, Dubourg O and Komajda M Experience from clinical genetics in hypertrophic cardiomyopathy: Proposal for new diagnostic criteria in adult members of affected families. Heart 77: 130-132, 1997.

17. Cerqueira MD, Weissman NJ, Dilsizian V, Jacobs AK, Kaul S, Laskey WK, Pennell DJ, Rumberger JA, Ryan T and Verani MS; American Heart Association Writing Group on Myocardial Segmentation and Registration for Cardiac Imaging: Standardized myocardial segmentation and nomenclature for tomographic imaging of the heart. A statement for healthcare professionals from the cardiac Imaging committee of the council on clinical cardiology of the American Heart Association. Circulation 105: 539-542, 2002.

18. Elliott P and McKenna WJ: Hypertrophic cardiomyopathy. Lancet 363: 1881-1891, 2004.

19. Van Driest SL, Ommen SR, Tajik AJ, Gersh BJ and Ackerman MJ: Sarcomeric genotyping in hypertrophic cardiomyopathy. Mayo Clin Proc 80: 463-469, 2005.

20. Van Driest SL, Vasile VC, Ommen SR, Will ML, Tajik AJ, Gersh BJ and Ackerman MJ: Myosin binding protein C mutations and compound heterozygosity in hypertrophic cardiomyopathy. J Am Coll Cardiol 44: 1903-1910, 2004.

21. Barefield D and Sadayappan S: Phosphorylation and function of cardiac myosin binding protein- $\mathrm{C}$ in health and disease. $\mathrm{J}$ Mol Cell Cardiol 48: 866-875, 2010.

22. Oakley CE, Chamoun J, Brown LJ and Hambly BD: Myosin binding protein-C: Enigmatic regulator of cardiac contraction. Int J Biochem Cell Biol 39: 2161-2166, 2007.

23. Geisterfer-Lowrance AA, Christe M, Conner DA, Ingwall JS, Schoen FJ, Seidman CE and Seidman JG: A mouse model of familial hypertrophic cardiomyopathy. Science 272: 731-734, 1996.

24. Michele DE, Gomez CA, Hong KE, Westfall MV and Metzger JM: Cardiac dysfunction in hypertrophic cardiomyopathy mutant tropomyosin mice is trans-gene-dependent, hypertrophy-independent, and improved by beta-blockade. Circ Res 91: 255-262, 2002.

25. Elliott P, Andersson B, Arbustini E, Bilinska Z, Cecchi F, Charron P, Dubourg O, Kühl U, Maisch B, McKenna WJ, et al: Classification of the cardiomyopathies: A position statement from the European society of cardiology working group on myocardial and pericardial diseases. Eur Heart J 29: 270-276, 2008.

26. Van Driest SL, Vasile VC, Ommen SR, Will ML, Tajik AJ, Gersh BJ and Ackerman MJ: Myosin binding protein C mutations and compound heterozygosity in hypertrophic cardiomyopathy. J Am Coll Cardiol 44: 1903-1910, 2004.

27. Spirito $\mathrm{P}$ and Maron BJ: Relation between extent of left ventricular hypertrophy and diastolic filling abnormalities in hypertrophic cardiomyopathy. J Am Coll Cardiol 15: 808-813, 1990.

28. Nagueh SF, Bachinski LL, Meyer D, Hill R, Zoghbi WA, Tam JW, Quiñones MA, Roberts R and Marian AJ: Tissue Doppler imaging consistently detects myocardial abnormalities in patients with hypertrophic cardiomyopathy and provides a novel means for an early diagnosis before and independently of hypertrophy. Circulation 104: 128-130, 2001.

29. Marsan NA, Tops LF, Nihoyannopoulos P, Holman ER and Bax JJ: Real-time three dimensional echocardiography: Current and future clinical applications. Heart 95: 1881-1890, 2009.

30. McKenna WJ, Stewart JT, Nihoyannopoulos P, McGinty F and Davies MJ: Hypertrophic cardiomyopathy without hypertrophy: Two families with myocardial disarray in the absence of increased myocardial mass. Br Heart J 63: 287-290, 1990. 